\title{
A Lei 10.639/03 como instrumento político-pedagógico na perspectiva da Interculturalidade
}

\author{
Law 10.639 / 03 as a political-pedagogical instrument \\ in the perspective of Interculturality
}

\author{
Antonio de Assis Cruz Nunes \\ Doutor em Educação. Coordenador e Professor do Programa de Pós- \\ Graduação em Gestão de Ensino da Educação Básica da Universidade \\ Federal do Maranhão (PPGEEB/UFMA), São Luís, MA - Brasil \\ antonio.assis@ufma.br \\ Andréa Luisa Frazão Silva \\ Discente do Mestrado Profissional em Artes da Universidade Estadual \\ de Santa Catarina (Prof-Artes/UFMA), São Luís, MA - Brasil \\ andreafrasi@hotmail.com
}

\author{
Luís Félix de Barros Vieira Rocha \\ Discente do Programa de Pós-Graduação em Gestão de \\ Ensino da Educação Básica da Universidade Federal do \\ Maranhão (PPGEEB/UFMA), São Luís, MA - Brasil \\ felix_rocha_luis@yahoo.com.br
}

Resumo: O presente artigo trata sobre a Lei n ${ }^{\circ}$ 10.639/2003 como instrumento político-pedagógico na perspectiva da Interculturalidade. O estudo faz, primeiramente, uma breve trajetória histórica de algumas ações dos movimentos sociais negros no Brasil até a aprovação da Lei 10.639 de 2003. A discussão ancorou-se, basicamente, por meios da referida Lei e seus congêneres, como: a Resolução N ${ }^{\circ}$ 01/2003, O Parecer N N 03/2004, O Plano Nacional de Implementação das Diretrizes Curriculares Nacionais para Educação das Relações Étnico-Raciais e para o Ensino de História e Cultura Afro-brasileira e Africana e autores que tratam sobre a temática das relações étnicoraciais, tais como: Candau (2016; 2012), Fleuri (2005), Santos (2005), Siss (2003), Silva (2005) Rocha (2011), dentre outros. A pesquisa concluiu que a Lei 10.639/03 pode se constituir como um forte instrumento político e pedagógico para o combate do preconceito e discriminação racial no contexto do multiculturalismo crítico ou da interculturalidade.

Palavras-chave: Lei 10.639/03. Interculturalidade. Educação.

\begin{abstract}
This article deals with Law 10.639/2003 as a political-pedagogical instrument in the perspective of Interculturality. The study firstly deals with a brief historical trajectory of some actions of black social movements in Brazil until the approval of Law 10.639 of 2003. The discussion was basically anchored by means of the referred Law and its congeners, such as: Resolution No. 01/2003, Opinion No. 03/2004, The National Plan for the Implementation of the National Curricular Guidelines for the Education of Ethnic and Racial Relations and for the Teaching of Afro-Brazilian and African History and Culture and authors dealing with the theme of ethnic-racial relations such as Candau (2016; 2012), Fleuri (2005), Santos (2005), Siss (2003), Silva (2005) Rocha (2011), among others. The research concluded that Law 10.639/03 can constitute a strong political and pedagogical instrument for combating prejudice and racial discrimination in the context of critical multiculturalism or interculturality.
\end{abstract}

Keywords: Law 10.639/03. Interculturality. Education. 


\section{Introdução}

Os estudos voltados para a educação das relações étnico-raciais, sobretudo sobre a população afro-brasileira, têm apresentado um aumento desde a década de 1990. Neste contexto, a temática do multiculturalismo também teve destaque em uma parcela das publicações acadêmicas. A referida temática tinha como referência a perspectiva norte-americana das políticas de ações afirmativas da população negra. (FLEURI, 2005).

Embora grande parte da literatura acadêmica aponte os Estados Unidos como precursor do multiculturalismo, outras literaturas descrevem que outros países o desenvolveram, a exemplos de países da Europa, América do Sul e Central. (SEMPRINI, 2003).

A utilização do termo multiculturalismo, na maioria das vezes, tem se generalizado com um único significado: promover uma integração e assimilação de várias culturas externas a uma dada cultura interna. É preciso dizer que se tratam de concepções, e que para o presente estudo apresentamos as compreensões que o referido termo tem tido.

Conforme Candau (2005), o termo multiculturalismo é de origem anglosaxônica, e tem como significado a junção de várias culturas diferentes em uma dada realidade físico-social cultural. Esse significado, ou entendimento, tomou forma científico-sociológica a partir dos estudos das relações étnicoculturais da sociedade norte-americana, da segunda metade do século XIX até a década de 1950.

Candau (2012) descreve que o multiculturalismo pode ser classificado de três formas, a saber: multiculturalismo assimilacionista, multiculturalismo diferencialista e multiculturalismo interativo ou intercultural.

O multiculturalismo assimilacionista refere-se à noção de que uma cultura dominante deve impor seus valores, tradições e costumes culturais às culturas, ditas coadjuvantes, por um processo de assimilação. Dessa forma:

Os grupos pertencentes a culturas externas são acolhidos pela cultura dominante, ou melhor, defende-se a ideia de que esses grupos de culturas externas serão capazes de se organizar para, com o grupo pertencente à cultura dominante, estabelecer um debate e chegar a um ponto comum. Dessa forma, torna-se parte 
da cultura dominante, sendo absorvida/assimilada por ela. (SILVA, 2005, p. 22).

O multiculturalismo diferencialista enfatiza que em uma dada formação cultural existem culturas diferentes, porém estas não precisam assimilar e estabelecer interações com a cultura dominante. Neste sentido, terminam sendo culturas isoladas e marginalizadas no interior de uma cultura dominante. Conforme Sen (2006), esse tipo de multiculturalismo é denominado de monocultura plural e, nesse contexto, não se deve promover somente a assimilação, sob pena de negar e silenciar as diferentes culturas presentes numa dada formação cultura dominante.

o multiculturalismo interativo é aquele que concebe a reunião de várias culturas estabelecendo interações e diálogos numa dada formação cultural, dita dominante. Candau (2012) prefere denominar esse tipo de multiculturalismo como Intercultural, na medida que o prefixo inter possui o entendimento de vários elementos em parceria, em diálogo, no processo de movimento dialético. Neste sentido, a referida autora se posiciona:

No entanto, situo-me na terceira perspectiva, que propõe um multiculturalismo aberto e interativo, que acentua a interculturalidade, por considerá-la a mais adequada para a construção de sociedades democráticas que articulem políticas de igualdade com políticas de identidade e reconhecimento dos diferentes grupos culturais (CANDAU, 2012, p. 26).

A interculturalidade no contexto educacional é também denominada de multiculturalismo crítico ou sociopolítico. Silva (2005, p. 35) diz:

Este modelo salienta a preocupação tanto de professores como de alunos em modificar as situações sociais e culturais, assim como aspectos ideológicos que provocam a discriminação racial. Essa perspectiva aceita os conflitos que surgem das inter-relações humanas como elemento motivador e provocador.

A partir do referencial da interculturalidade e/ou do multiculturalismo crítico, o presente artigo se insere neste contexto, tendo como demarcação de estudo 
a Lei 10.639, que no dia 09 de janeiro do ano 2003 foi aprovada para atender as reivindicações de décadas dos movimentos sociais negros. Neste sentido, o estudo se coaduna com a perspectiva do multiculturalismo crítico quando prescreve que:

Deve trabalhar na perspectiva de construção da democracia, estabelecida como meta, inserida em uma política crítica e de compromisso com a justiça social. Questões específicas relativas a raça, gênero e classe são vistas como produto ou resultado das lutas sociais mais amplas e, finalmente, a diferença é compreendida como produto da história (SILVA, 2005, p. 35).

Do exposto, consideramos que a Lei 10.639 é um instrumento políticopedagógico dentro do referencial multiculturalista crítico ou intercultural, haja vista as exposições teóricas, acima descritas.

\section{Contextualização histórica da Lei 10.639/03}

Para entendermos a conjuntura da aprovação da Lei 10.639/03, consideramos, primeiramente, necessário descrevermos vários acontecimentos e caminhos na história que desencadearam algumas mudanças em prol do segmento étnico-racial.

O percurso histórico busca entender de que forma as lutas políticas, históricas, sociais e jurídicas foram importantes para o desenvolvimento da ideologia da igualdade racial no Brasil, tendo desencadeado tantos eventos, congressos, leis e pareceres que tratam sobre as relações étnico-raciais. Essas lutas se iniciaram basicamente no período da escravatura até á promulgação da Lei 10.639 de 2003.

Inicialmente a legislação educacional impedia o negro no acesso à educação. Sobre essa situação, o Decreto 1.331-A, de 17 de fevereiro de 1854 regulamentava no artigo 69:

$\S 1^{\circ}$ Os meninos que padecerem molestias contagiosas.

$\S 2^{\circ}$ Os que não tiverem sido vaccinados.

$\S 3^{\circ}$ Os escravos. (BRASIL, 2018, p.17) 
Assim, os professores não eram obrigados a ensinar aos negros, entretanto, se quisessem poderiam lecionar aos sábados, domingos e dias santos.

Segundo Rocha (2011, p. 17),

o Decreto $\mathrm{n}^{\circ}$ 7.031-A de 6 de setembro de 1878, por sua vez, estabelecia que os negros só poderiam estudar no período noturno. A escola noturna era aberta apenas a clientela adulta, maior de 14 anos e essencialmente masculina. Uma lei complementar de 5 de dezembro de 1824 proíbe o leproso e o negro de frequentar a escola pública.

Desta forma o Decreto $n^{\circ}$ 7.031-A de 6 de setembro de 1878, que instituía que os negros só podiam estudar no período noturno e outras manobras, foi lançado no intuito de impedir a população negra de frequentar escola.

Perante a configuração social estabelecida no período da Abolição da Escravatura, a República no Brasil buscava a reestruturação do país. De um lado, a abolição conferiu aos escravos, anteriormente vistos como alheios, a condição de pessoa humana e a Primeira Constituição da República predizendo a concessão da cidadania e igualdade. (CUNHA JÚNIOR, 2011).

Nos períodos do final do Império e início da República, os imigrantes tiveram investimento do Estado brasileiro para que pudessem se adaptar no país, enquanto os negros que, por tanto tempo foram mão de obra gratuita, acabaram relegados à falta de escolarização e marginalização social pela ausência de políticas públicas. (MOURA, 1988).

Rocha (2011, p.17) diz que:

De acordo com alguns autores, a educação foi um elemento que se levou em conta durante o processo de abolição do trabalho escravo. Era necessário que se formassem quadros de trabalhadores necessários à sociedade livre. Pode-se dizer que houve uma preocupação do poder público com a importância da educação como elemento de inclusão social. Mas tal inclusão, para os ex-escravos e seus descendentes, realizou-se de forma absolutamente marginal, pois constitui uma dualidade do ensino, representando as desigualdades entre dois grupos sociais. 
Havia uma escola para anteder à sociedade da época com suas necessidades e outra para os trabalhadores. Em outros termos: a escola diferente para públicos específicos nos quais uns têm acesso à riqueza material e os outros não.

Contudo, apesar da Abolição da escravatura na fase inicial do período republicano, a inclusão social e educacional para negros e seus descendentes foi colocada de forma limitada. Havia um pensamento arraigado pela visão eurocêntrica da ideologia de supremacia racial que reforçava os estereótipos enfatizando a marginalização e não acesso à educação. (SISS, 2003).

A Constituição da República dos Estados Unidos do Brasil, datada de 1891 no parágrafo $6^{\circ}$, do art. 72 , não se atentou para efetiva implantação das premissas da igualdade racial, mostrando-se contrária, invisibilizando mais uma vez os desfavorecidos historicamente na sociedade, evidenciados nos parágrafos $1^{\circ}$ e $2^{\circ}$ do art. 70 , que excluíam dos direitos políticos os mendigos e os analfabetos, condição que se situava a maioria dos negros ex-escravos. (ROCHA, 2013).

Do exposto:

Durante o período colonial até a República, a educação popular, como é entendida hoje, não foi uma preocupação para o poder público. A grande maioria dos escravos não frequentou a escola, pois seu tempo era exigido quase que exclusivamente para atividade produtiva. A Igreja Católica, na época responsável pelos ensinos primário e secundário, possibilitou somente a brancos e ricos receber esta formação, que era a eles oferecida no próprio lar ou diretamente com os Jesuítas nos conventos. Filhos de colonos tinham oportunidades de aprender a ler e escrever, progredindo, assim, no campo educacional, enquanto segundo Marcus Vinícius Fonseca (2001), a escolarização de negro e índios 'realiza-se apenas entre as brechas do sistema colonial e como forma de resistência e contestação. Legalmente, no Brasil vigorava a determinação de se negar acesso à leitura e escrita aos escravos. Mesmo que os senhores se propusessem a arcar com os custos, a educação, com as características escolares, era negada aos escravos'. (ROCHA 2011, p.16). 
As discussões acerca das questões raciais no Brasil foram tomando corpo e formaram-se grupos. Neste sentido, a Lei Afonso Arinos, de 1951, foi o primeiro dispositivo jurídico para combater atos discriminatórios, que a partir de então passaram a ser consideradas contravenções.

A partir da década de 1940 até a década de 1970, vários movimentos sociais negros eclodiram na direção da inserção social da população afro-brasileira. À guisa de exemplos, têm-se as associações político-culturais como: o (TEN) Teatro Experimental Negro, em 1944, o Conselho Nacional de Mulheres Negras e o I Congresso do Negro Brasileiro, em 1950, o Movimento Negro Unificado (MNU), em 1978. (SANTOS, 2005).

$\mathrm{Na}$ década de 1970, foram surgindo outras organizações voltadas para o fortalecimento da identidade negra nacional pautada na luta contra a discriminação e o preconceito, e contrárias ao mito da democracia racial estabelecido em nosso país. Esses grupos debatiam alternativas para a diminuição da disparidade e desigualdade racial. Entre outros fatores, os movimentos atentaram-se para a questão educacional como ponto fundamental, visto que se perpetuava por anos um sistema educacional excludente. (SANTOS, 2005).

Importante acrescentar a descrição de Candau (2010, p.159) quando compara os movimentos sociais negros, a partir da realidade brasileira, com outras realidades na América Latina:

Os movimentos negros organizados têm também promovido leituras alternativas do processo histórico vivido e do papel dos negros na formação dos vários países latino-americanos. Demandas por reparações por parte dos estados e das sociedades, por medidas que visem ressarcir os afro-descendentes dos danos sofridos sob o regime escravista, assim como pelas políticas explícitas ou tácitas de embranquecimento da população são apresentadas e se referem a diferentes âmbitos sociais, políticos e culturais.

Na década de 1980, ocorreram também vários debates sobre as condições da educação para a população negra no país. No ano de 1983, o então Deputado Federal, Abdias do Nascimento propôs o Projeto de Lei $n^{\circ} 1.332 / 83$, o qual previa a inclusão do ensino de História e Cultural Africana e Afro-brasileira na educação 
primária, secundária e superior. Porém, o referido projeto não foi aprovado. (MÜLLER \& COELHO, 2013). Foi o embrião da Lei 10.639/03.

Em relação à aprovação da Constituição Federal de 1988, Santos (2005) considera que esta teve grande influência e participação efetiva dos movimentos sociais, entre eles, o movimento de educadores e negros. Ela representou um marco, pois, diferentemente das constituições anteriores, trouxe como uma de suas premissas a rejeição ao preconceito, à discriminação e ao racismo, representando um avanço significativo para a sociedade brasileira.

O inciso IV, do Artigo $3^{\circ}$ da Constituição Federal, de 1988, ratifica a necessidade de combater a discriminação nas relações sociorraciais, vejamos: "promover o bem de todos, sem preconceitos de origem, raça, sexo, cor, idade e quaisquer outras formas de discriminação". (BRASIL, 2004a, p. 7).

Outra conquista dos movimentos sociais afro-brasileiros na Constituição Federal de 1988 é o direito de terras para a população quilombola. Eis o que diz o Artigo 68: "Aos remanescentes das comunidades dos quilombos que estejam ocupando suas terras é reconhecida a propriedade definitiva, devendo o Estado emitir-lhes os títulos respectivos". (BRASIL, 2004a, p. 25).

Também o Artigo 216, Inciso V, Parágrafo $5^{\circ}$ insere outra garantia constitucional à população quilombola. Vejamos: "Ficam tombados todos os documentos e os sítios detentores de reminiscências históricas dos antigos quilombos". (BRASIL, 2004a, p. 41).

Na década de 1990, tem-se como marco a Marcha Zumbi dos Palmares, em 1995, que estabeleceu o grito sobre a condição do negro no Brasil, desencadeado em um programa nacional de enfrentamento das desigualdades raciais no país. (MÜLLER \& COELHO, 2013).

No dia 09 de janeiro do ano 2003, foi aprovada e promulgada a Lei Federal $\mathrm{n}^{\circ}$ 10.639, que foi instituída no governo do Presidente da República Luiz Inácio Lula da Silva, atendendo as reivindicações de décadas do Movimento Negro, que vinha há anos lutando para que o Estado reconhecesse o racismo à brasileira e derrubasse o mito da democracia racial.

A Lei 10.639/2003 versa que a cultura e história afro-brasileira esteja inserida no currículo escolar. As Diretrizes Curriculares Nacionais para a Educação das Relações Étnico-Raciais e para o Ensino de História e Cultura Afro-Brasileira e Africana aprovam e fundamentam a inclusão da lei, que tem como desígnio corrigir injustiças, combater discriminações e preconceitos, corrigir injustiças 
enfatizando a inclusão social e o exercício pleno da cidadania aqueles que estão inseridos no sistema educacional brasileiro. (BRASIL, 2008).

Consideramos que, na perspectiva da interculturalidade, a Lei 10.639/03 visa ultrapassar o enfoque educacional, uma vez que este se intercruza com outros elementos da vida social. Neste sentido, nossa compreensão se coaduna com Candau (2010, p.66) quando descreve o seguinte:

A interculturalidade é então concebida como uma estratégia ética, política e epistêmica. Nesta perspectiva, os processos educativos são fundamentais. Por meio deles questiona-se a colonialidade presente na sociedade e na educação, desvela-se o racismo e a racialização das relações, promove-se o reconhecimento de diversos saberes e o diálogo entre diferentes conhecimentos, combate-se as diferentes formas de desumanização, estimula-se a construção de identidades culturais e o empoderamento de pessoas e grupos excluídos, favorecendo processos coletivos na perspectiva de projetos de vida pessoal e de sociedades 'outras'.

As Diretrizes evidenciam a necessidade de políticas especiais que revertam o padrão excludente estabelecido no Brasil, que, historicamente, impediram a muitos brasileiros negros acesso à educação escolar e sua permanência. (BRASIL, 2008).

Conforme o Parecer $\mathrm{N}^{\circ}$ 03/2004, a Lei 10.639/03 foi criada com a finalidade de combater o racismo, reconhecendo a história da cultura afro-brasileira e africana na constituição do nosso país, assim como é um instrumento para a construção de uma educação voltada ao respeito da diversidade cultural e social brasileira, combatendo todas as formas de preconceito, o racismo e todas as formas de discriminação. (BRASIL, 2004b).

Ainda o referido Parecer descreve que o combate ao racismo deve se dar por meio de pedagogias propícias a isso. Neste sentido, assinala:

Pedagogias de combate ao racismo e a discriminações elaboradas com o objetivo de educação das relações étnico/raciais positivas têm como objetivo fortalecer entre os negros e despertar entre os brancos a consciência negra. Entre os negros, poderão 
oferecer conhecimentos e segurança para orgulharem-se da sua origem africana; para os brancos, poderão permitir que identifiquem as influências, a contribuição, a participação e a importância da história e da cultura dos negros no seu jeito de ser, viver, de se relacionar com as outras pessoas, notadamente as negras. Também farão parte de um processo de reconhecimento, por parte do Estado, da sociedade e da escola, da dívida social que têm em relação ao segmento negro da população, possibilitando uma tomada de posição explícita contra o racismo e a discriminação racial e a construção de ações afirmativas nos diferentes níveis de ensino da educação brasileira. (BRASIL, 2004b, p.16-17).

O Parecer $\mathrm{N}^{\circ}$ 03/04 acrescenta sobre as pedagogias de combate ao racismo:

Tais pedagogias precisam estar atentas para que todos, negros e não negros, além de ter acesso a conhecimentos básicos tidos como fundamentais para a vida integrada à sociedade, exercício profissional competente, recebam formação que os capacite para forjar novas relações étnico-raciais. Para tanto, há necessidade, como já vimos, de professores qualificados para o ensino das diferentes áreas de conhecimentos e, além disso, sensíveis e capazes de direcionar positivamente as relações entre pessoas de diferente pertencimento étnico-racial, no sentido do respeito e da correção de posturas, atitudes, palavras preconceituosas. Daí a necessidade de se insistir e investir para que os professores, além de sólida formação na área específica de atuação, recebam formação que os capacite não só a compreender a importância das questões relacionadas à diversidade étnico-racial, mas a lidar positivamente com elas e sobretudo criar estratégias pedagógicas que possam auxiliar a reeducá-las.(BRASIL, 2004b , p.20).

Importante registrarmos que a obrigatoriedade do ensino da História e Cultura Afro-brasileira e Africana não deve se restringir apenas às disciplinas sugeridas pela Lei 10.639/03, como Educação Artística, Literatura e História 
do Brasil, mas pode ser ensinado em outros contextos didático-pedagógicos. O Parecer N ${ }^{\circ} 03 / 2004$ aponta para essa direção:

O ensino de História e Cultura Afro-Brasileira e Africana, a educação das relações étnico-raciais, tal como explicita o presente parecer, se desenvolverão no cotidiano das escolas, nos diferentes níveis e modalidades de ensino, como conteúdo de disciplinas,(4) particularmente, Educação Artística, Literatura e História do Brasil, sem prejuízo das demais(5), em atividades curriculares ou não, trabalhos em salas de aula, nos laboratórios de ciências e de informática, na utilização de sala de leitura, biblioteca, brinquedoteca, áreas de recreação, quadra de esportes e outros ambientes escolares. (BRASIL, 2004b, p.20).

Outro documento que baliza a Lei 10.639/03 é o Plano Nacional de Implementação das Diretrizes Curriculares Nacionais para Educação das Relações Étnico-Raciais e para o Ensino de História e Cultura Afro-brasileira e Africana. No tópico do Ensino Fundamental o Plano diz:

No Ensino Fundamental, o ato de educar implica uma estreita relação entre as crianças, adolescentes e os adultos. Esta relação precisa estar pautada em tratamentos igualitários, considerando a singularidade de cada sujeito em suas dimensões culturais, familiares e sociais. Nesse sentido, a educação das relações étnicoraciais deve ser um dos elementos estruturantes do projeto político pedagógico das escolas. (BRASIL, 2009, p. 49).

O Plano de Implementação da Lei 10.639/03 aponta Ações Principais para o Ensino Fundamental, dentre elas, destacamos a necessidade de formações iniciais e continuadas para a assimilação ativa de conteúdos acerca da temática negra e indígena. Eis o teor do texto: "Assegurar formação inicial e continuada aos professores e profissionais desse nível de ensino para a incorporação dos conteúdos da cultura Afro-brasileira e Indígena e o desenvolvimento de uma educação para as relações étnico-raciais". (BRASIL, 2009, p. 50). 
Uma das dificuldades que muitas escolas brasileiras têm em seu cotidiano pedagógico é trabalhar de forma interdisciplinar, uma vez que o ideário positivista, pautado na perspectiva de ver um objeto isolado sem a necessidade de colocá-lo como uma parte que se articula com um todo dialético ${ }^{1}$, termina desenvolvendo um ensino de conhecimentos isolados epistemologicamente. Dessa forma, o Plano de Implementação da Lei 10.639/03 aponta para essa perspectiva de se trabalhar de forma interdisciplinar, vejamos: "Abordar a temática étnico-racial como conteúdo multidisciplinar e interdisciplinar durante todo o ano letivo, buscando construir projetos pedagógicos que valorizem os saberes comunitários e a oralidade, como instrumentos construtores de processos de aprendizagem". (BRASIL, 2009, p. 50).

Encerramos dizendo que o ensino de conteúdos referentes à História e Cultura Afro-brasileira e Africana não deve ser apenas responsabilidade dos professores e professoras, mas de todos os agentes inseridos no contexto escolar, que vai desde a direção escolar até a coordenação pedagógica. Sobre isso o Artigo $3^{\circ}$, da Resolução $\mathrm{N}^{\circ} 01 / 2004$ assinala:

A Educação das Relações Étnico-Raciais e o estudo de História e Cultura Afro-Brasileira, e História e Cultura Africana será desenvolvida por meio de conteúdos, competências, atitudes e valores, a serem estabelecidos pelas Instituições de ensino e seus professores, com o apoio e supervisão dos sistemas de ensino, entidades mantenedoras e coordenações pedagógicas, atendidas as indicações, recomendações e diretrizes explicitadas no Parecer CNE/CP 003/2004. (BRASIL, 2004c, p.1)

\section{Conclusão}

A aprovação da Lei 10.639/03 constitui-se com um importante marco legal para a educação afro-brasileira, haja vista que depois de 115 anos, após a Abolição da Escravidão Negra no Brasil (grifo nosso), o país reconheceu que a população afro-brasileira, sobretudo a que possui tez escura, padece de um longo histórico de marginalização e abandono social. Vimos que até a sua aprovação, várias organizações sociais negras no complexo jogo dialético erigiram lutas de 
inserção sociorraciais nas relações raciais brasileiras. Assim, a tão enaltecida Democracia Racial Brasileira ${ }^{2}$, forjada desde o final da última metade do século XIX, e ganhando estatuto sociológico nas obras de Gilberto Freire, terminou colocando empecilhos para a população afro-brasileira nas garantias individuais e coletivas nos campos da educação, saúde, moradia e outros.

Todavia, mesmo que a democracia racial brasileira não tenha tido uma fase áurea em muitas mentalidades brasileiras, as bandeiras de lutas dos movimentos negros conseguiram, de acordo com o seu tempo, desenvolver ações em prol do combate ao racismo. E neste bojo, há de se registrar a negação da tese da democracia racial brasileira pela tese do Mito da democracia racial brasileira ${ }^{3}$, o qual vai afirmar que existem preconceitos e discriminações sociorraciais entre os segmentos étnicoraciais, principalmente em relação aos indígenas e aos negros e negras.

Por meio do mito da democracia racial brasileira, diferentes movimentos sociais negros impeliram ações rumo ao combate do racismo e suas inserções no seio da vida social brasileira. Destacam-se aí, a aprovação da Constituição Federal de 1988, a Lei 9394/96 por meio das alterações da Lei 10.639/03 e, posteriormente, por meio da Lei 11.645/08, a Lei 12.711 (Lei de sistema de cotas étnico-raciais nas universidades e institutos federais) e a Lei 10.639/03 integralmente.

A Lei 10.639/03 é um instrumento legal importante para a população afrobrasileira, uma vez que permite ao sistema educacional brasileiro desenvolver várias ações político-pedagógicas no combate ao racismo, sentimento este que traz consequências nefastas ao convívio humano. Neste sentido, o Artigo $2^{\circ}$, da Resolução lei de forma visionária afirma:

As Diretrizes Curriculares Nacionais para a Educação das Relações Étnico-Raciais e para o Ensino de História e Cultura Afro-Brasileira e Africanas constituem-se de orientações, princípios e fundamentos para o planejamento, execução e avaliação da Educação, e têm por meta, promover a educação de cidadãos atuantes e conscientes no seio da sociedade multicultural e pluriétnica do Brasil, buscando relações étnico-sociais positivas, rumo à construção de nação democrática.

$\mathrm{Na}$ perspectiva da interculturalidade, a referida Lei chancela a necessidade "para a construção de sociedades democráticas, que articulem políticas de igual- 
dade com políticas de identidade". (CANDAU, 2016, p.808). Assim, consideramos que o ensino da História e Cultura da População Africana e Afro-brasileira poderá permitir tomadas de consciência identitária, tanto por parte dos não-negros, quanto dos negros que passam a conhecer e compreender o povo negro como construtores e protagonistas de inúmeras histórias invisibilizadas nos livros escolares e nas pesquisas acadêmicas.

\section{Notas}

1 Segundo Kosik (1976), em uma estrutura existe um todo dialético formado por partes que desenvolvem influxos e refluxos que se movem dialeticamente. Neste sentido, uma parte não funciona sozinha, ela precisa se articular com outras partes para continuar se movendo.

2 A Democracia Racial Brasileira é uma tese aperfeiçoada e desenvolvida pelo sociólogo Gilberto Freire, a qual afirma que no Brasil não existem preconceitos e discriminações raciais entre os grupos étnico-raciais (indígena, negro e branco). (GUIMARÃES, 1999).

3 Florestan Fernandes, na década de 1960, cunhou esse termo ao afirmar que no Brasil o racismo é velado e/ou mascarado. Dessa forma, concluiu que o brasileiro tem preconceito de ter preconceito por uma longa tradição histórica de se acreditar que no país todas as etnias se relacionam harmoniosamente. Todavia, suas pesquisas em conjunto com outros dados apontavam para um desnível sociorracial. Assim, afirmou que a democracia racial não passa de um mito.

\section{Referências}

BRASIL. Constituição Federal de 1988. São Paulo: Saraiva, 2004a.

Lei $N^{\circ}$ 10.639, de 9 de Janeiro de 2003. Brasília, 2008. Disponível em: < http:// www.planalto.gov.br/ccivil_03/leis/2003/L10.639.htm>. Acesso em 20 jan 2018.

. Parecer $n^{\circ}$ 003, de 10 de março de 2004. Brasília, 2004b. Disponível em: $<$ http://portal.mec.gov.br/dmdocuments/cnecp_003.pdf>. Acesso em 20 jan 2018.

Resolução $N^{o}$ 1, de 17 de Junbo de 2004. Brasília, 2004c. Disponível em: $<$ http://portal.mec.gov.br/cne/arquivos/pdf/res012004.pdf>. Acesso em 20 jan 2018.

Plano Nacional de Implementação das Diretrizes Curriculares Nacionais para Educação das Relações Etinico-Raciais e para o Ensino de História e Cultura Afrobrasileira e Africana. Brasília, 2009. 
Decreto 1.331-A, de 17 de fevereiro de 1854. Câmara dos Deputados.

Brasília, 2018. Disponível em:<http://www2.camara.leg.br/legin/fed/decret/1824-1899/ decreto-1331-a-17-fevereiro-1854-590146-publicacaooriginal-115292-pe.html>. Acesso em: 20 mar 2018.

CANDAU, Vera Maria Ferrão. Cotidiano escolar e práticas interculturais. Cadernos de Pesquisa, São Paulo, v. 46, n. 161, p.802-820, jul.-set.2016. Disponível em: < http://www. scielo.br/pdf/cp/v46n161/1980-5314-cp-46-161-00802.pdf>. Acesso em: 12 maio 2018.

Diferenças culturais, interculturalidade e educação em direitos humanos.

Cadernos Cedes, Campinas, v. 33, n. 118, p. 235-250, jan.-mar. 2012. Disponível em: < http:// www.scielo.br/pdf/es/v33n118/v33n118a15.pdf>. Acesso em: 12 maio 2018.

Interculturalidade e Educação na América Latina. uma construção plural, original e complexa. Revista Diálogo Educacional, Curitiba, v. 10, n. 29, p. 151-169, jan.-abr. 2010.

Reiventar a escola. 4. ed. Petrópolis (RJ): Vozes, 2005.

CUNHA JUNIOR, Henrique. Africanidades e educação: pensando sobre a inclusão universitária dos afrodescendentes. In: AQUINO, Mirian Albuquerque; GARCIA, Joana Coeli Ribeiro (Org.). Responsabilidade ético-social das universidades públicas e a educação da população negra. João Pessoa: Universitária da UFPB, 2011. p. 61-70.

FLEURI, Reinaldo Matias (Org.). Educação intercultural: mediações necessárias. Rio de Janero: DP\&A, 2005.

GUIMARÃES, Antonio Sérgio Alfredo. Racismo e anti-racismo no Brasil. São Paulo: Editora 34, 1999.

KOSIK, Karel. Dialética do concreto. Rio de Janeiro: Paz e Terra, 1976.

MOURA, Clóvis. Sociologia do negro brasileiro. São Paulo: Ática, 1988.

MÜLLER. Tânia Mara Pedroso. COELHO Wilma de Nazaré Baía. A Lei Nº 10.639/03 e a formação de professores: trajetória e perspectivas. Revista da ABPN, v. 5, n. 11 jul./out. 2013, p. 29-54.

ROCHA, Solange. SILVA, José Antonio Novaes da. À luz da Lei 10.639/03, avanços e desafios: movimentos sociais negros, legislação educacional e experiências pedagógicas. Revista da $A B P N$, v. 5, n. 11, jul./out. 2013, p. 55-82.

ROCHA, Rosa Margarida de Carvalho. Educação das relações étnico-raciais: pensando referenciais para a organização da prática pedagógica. Belo Horizonte: Mazza Edições, 2011.

SANTOS, Sales Augusto dos. A Lei no 10.639/03 como fruto da luta anti-racista do Movimento Negro. In BRASIL. Educação anti-racista: caminhos abertos pela Lei Federal $n^{\circ}$ 10.639/03. Brasília: Ministério da Educação, Secretaria de Educação Continuada, Alfabetização e Diversidade, p.21-37, 2005. Disponível em: < http://unesdoc.unesco.org/ images/0014/001432/143283por.pdf $>$. Acesso em: 06 jul. 2018.

SEMPRINI, Andrea. Multiculturalismo. Tradução de Loureano Pelegrin. São Paulo: Edusc, 2003. 
SILVA, Gilberto Ferreira da. Multiculturalismo e educação intercultural: vertentes históricas e repercussões atuais na educação. In: FLEURI, Reinaldo Matias (Org.). Educação intercultural: mediações necessárias. Rio de Janeiro: DP\&A, 2005.

SISS, Ahyas. Afro-Brasileiros, cotas e ação afirmativa: razões históricas. Niterói (RJ):

PENESB, 2003.

Para referenciar este texto:

NUNES, A. A. C.; SILVA, A. L. F.; ROCHA, L. F. B. V. A Lei 10.639/03 como instrumento político-pedagógico na perspectiva da Interculturalidade. Dialogia, São Paulo, n. 29, p. 95-110, mai./ago. 2018. Disponível em: <https://doi.org/10.5585/Dialogia.n29.8766>. 